\title{
APUNTES SOBRE CODIFICACIÓN Y COSTUMBRE EN LA HISTORIA DEL DERECHO COLOMBIANO
}

\author{
MAURICIO GARCÍA VILLEGAS
}

There is, in Latin America, a general culture of non-observance of the law that has not been studied at length. In order to offer a historical perspective on the roots of this phenomenon, the article follows the development of the law and legal institutions during the colonial period and independence. Both periods show a divergence between the legal archetype that was sought to be implemented and the way that political and legal relationships actually developed in the American territory. This trait is particularly evident during the period of transition toward independence, in which the Enlightenment discourse was used to justify the rebellion against Spain and the creation of independent states, rather than to transform social structures and to include all individuals as rightful citizens of the new states.

En América Latina la actitud de las personas frente al derecho es ambivalente. Por un lado, creemos que el destino social está encadenado a decisiones legales cruciales sin las cuales la sociedad caería dentro de la anarquía y el caos. Sin embargo, por el otro lado, embargamos un fuerte sentimiento de independencia frente al derecho oficial, lo cual ocasionalmente toma la forma de rebeldía, o de una reivindicación de "derecho natural", que justifica el hecho de emprender acciones contra, o al margen, de lo prescrito. Así, en América Latina el derecho suele ser percibido no sólo como un instrumento de dominación de clase sino también como una fórmula futura para la redención social. Evoca resistencia tanto como inspira esperanza, todo ello en una especie de división temporal entre, por un lado, el contexto presente del individuo bajo los efectos de la dominación y, por otro lado, la sociedad futura emancipada. 
Esta disposición cultural ambivalente frente al derecho es con frecuencia evocada por escritores, políticos y cientistas sociales ${ }^{1}$; sin embargo, su mención no supera, por lo general, la simple evocación. Poco se ha hecho por analizar en detalle la cultura jurídica de los países latinoamericanos no obstante el creciente interés por el tema del derecho en los últimos años². Tampoco ha habido mayor preocupación por encontrar las raíces históricas de nuestra cultura jurídica no obstante la existencia de importantes estudios históricos del derecho, sobre todo referidos al período colonial ${ }^{3}$. Durante la última década sin embargo, algunos economistas interesados en el tema del desarrollo y vinculados con las teorías neoinstitucionales se han interesado por la cultura jurídica. En el capítulo tercero de esta investigación analizo el contenido y mérito de estos estudios. Por ahora, en este capítulo me concentro en la perspectiva histórica del incumplimiento al derecho.

Las raíces de la cultura de la inobservancia del derecho son particularmente visibles en el periodo de transición hacia la independencia cuando se recibieron e incubaron las ideas revolucionarias de mediados y finales del siglo XVIII provenientes de Europa y Estados Unidos, las cuales se unieron en intrincadas mezclas con la tradición jurídica española. Esto no significa, desde luego que el período colonial no sea importante para desentrañar tales raíces; por el contrario, significa que toda la importancia de la cultura jurídica colonial se aprecia de manera particularmente clara en la época en la cual dicha cultura entró en crisis. Aquí no pretendo, ni mucho menos, desentrañar estas raíces sólo intento establecer, a manera de hipótesis, algunas relaciones y hechos que me parecen significativos para la comprensión de este fenómeno cultural y que en el futuro podrían dar lugar a estudios históricos más profundos.

En lo que sigue trataré de explicar la existencia de una cultura del derecho flexible o dúctil en América Latina, que tiene origen en la vida colonial y mantiene una cierta continuidad hasta las repúblicas del siglo XIX y de allí hasta nuestros días. Mi interés por el período de la emancipación nace menos de su poder para transformar las prácticas jurídicas coloniales que de su capacidad para producir un tipo de derecho dotado de una enorme habilidad para mantenerse incólume a pesar de su ineficacia. Dicho en otros términos, la emancipación y su producción jurídica son interesantes,

\footnotetext{
${ }^{1}$ Véase por ejemplo, (O’Donnell 1998); (Nino 1989), (Nino 1992); (Keen 1996); (Linz 1996).

${ }^{2}$ Este interés se manifiesta, por ejemplo en temas tales como el constitucionalismo y la justicia como elementos esenciales para el logro de la transición hacia la democracia. Véase el capítulo 4 de esta investigación.

${ }^{3}$ Buena parte de estos estudios serán reseñados más adelante en este ensayo.
} 
a pesar de no haber logrado una ruptura con el pasado colonial, debido a que ella sirvió para reproducir y reforzar un tipo de derecho que viene desde la colonia y que se caracteriza su flexibilidad e ineficiencia ${ }^{4}$

Antes de iniciar debemos hacer algunas precisiones metodológicas. Los historiadores del derecho Indiano - y en general todos aquellos que estudian las relaciones entre el derecho y la sociedad - se debaten entre dos concepciones opuestas. La primera de ellas considera que las normas jurídicas son simples epifenómenos sociales que por sí mismo no tienen mayor significado. Solo el estudio de las relaciones sociales y, en particular de las relaciones económicas, puede dar una idea clara del sentido y alcance de los contenidos jurídicos. Según esta concepción, que durante la segunda mitad del siglo XX tuvo expresión en el Marxismo, las normas jurídicas son instrumentos políticos dependientes del poder dominante ${ }^{5}$. En contraste con esta, una segunda concepción estima que el derecho es un campo de acción social dotado de autonomía y capacidad para traducir sus postulados en realidades sociales. La hisoriografía de la Ilustración difundió esta manera de pensar que hoy en día sigue teniendo buen recibo en círculos gubernamentales encargados de diseñar las políticas públicas.

Ambas teorías tienen una visión del derecho de tipo instrumental; es decir consideran que lo jurídico es una herramienta para modificar una realidad social que le es externa. En este sentido se oponen a una tercera visión de tipo constructivista - que aquí se adopta - según la cual entre el derecho y los hechos existe una relación de recíproca incidencia. El derecho juega un papel importante en la configuración de la realidad social, o como se diría desde la sociología, el derecho juega un papel constitutivo de las relaciones sociales. Sin embargo ello no significa que la incidencia social del derecho pueda ser percibida con independencia de los hechos sociales dentro de los cuales opera. Normas y hechos históricos deben ser comprendidos en la plena complejidad de sus relaciones de influencia recíproca. En el campo de la historia del derecho en América hispánica ésta concepción ha sido defendida por autores tales como Mario Góngora, Ricardo Zorraquín, Alfonso García Gallo y Victor Tao Anzoategui'

\footnotetext{
${ }^{4}$ Al respecto puede verse (Levine 1956), (Romero 1985), (Romero 2001), (Góngora 1951), (García-Gallo 1972), (Ortiz 1960). "No importaba - afirma Romero - la forma de construcción teórica: actas, constituciones, planes políticos radicalizados, la realidad era el viejo mundo; la gente que seguía viviendo después del sagrado juramento revolucionario, vivía exactamente como la víspera" (Romero 2001).

${ }^{5}$ La llamada escuela braudeliana ilustra esta concepción del derecho. Véase (Braudel 1968) en el campo específico de la historia del derecho véase (Irving 1953); (Terán 1981)

${ }^{6}$ Véase por ejemplo (García-Gallo 1972, 1967; Góngora 1951); (Ots Capdequi 1940) y (Tau Anzoátegui 1992).
} 


\section{La Colonia}

El régimen colonial español fue el producto de la incorporación, adaptación y transformación del derecho metropolitano español, arraigado en la tradición medieval iusnaturalista europea, a las circunstancias complejas y variables que tuvieron lugar por aquel entonces en los territorios coloniales (Cutter 1999). El derecho español estaba consagrado en documentos tales como El Ordenamiento de Alcalá (1384) las leyes de Toro (1505), Nueva recopilación de castilla (1567) y Novísima recopilación de Castilla (1805). Subordinados a tales normas estaban los fueros o cartas municipales, los cuales debían ser aplicados a falta de norma real. En tercer lugar estaban las normas de derecho romano y canónico contenidas en las Siete Partidas de Alfonso X. Inicialmente en las Indias españolas se aplicaban las normas producidas en el régimen de castilla. En 1614 sin embargo, Pelipe II determinó que sólo tendrían vigor aquellas normas formuladas de manera específica para los territorios coloniales. Así se creó la Recopilación de las Indias de 1680 y el inicio de un orden legal específico en la América española.

Pero el derecho originado en castilla sólo era una fuente normativa entre otras, si bien, desde el punto de vista puramente formal, se le consideraba superior a las demás. Las normas locales emanadas de los virreyes, las audiencias, los gobernadores, los corregidores, los alcaldes y los cabildos, muchas de ellas fundadas en la costumbre y la equidad, comprendían el grueso del derecho aplicado en las indias y a este se le conoce como derecho indiano criollo. A medida que se desarrollaba el régimen colonial, las fuentes locales del derecho fueron ganando terreno, de tal manera que a finales del siglo XVIII el derecho indiano criollo había adquirido una entidad sustancialmente diferente a la del derecho castellano.

El resultado de la transferencia legal, desde España, a más de cinco mil kilómetros de distancia, hacia las Indias españolas, fue la creación de un derecho original y dotado de vínculos difusos frente a sus fuentes españolas. La relativa autonomía del derecho indiano con respecto al derecho español ha dado lugar a una interpretación crítica, en buena parte propiciada por los líderes la ilustración criolla del siglo XIX, según la cual el derecho Indiano se caracterizaba por su autoritarismo y su ineficacia. ${ }^{?}$

\footnotetext{
${ }^{7}$ Acorde con esta opinión, las nuevas repúblicas intentaron reemplazar el derecho dúctil y variable de la colonia con un derecho predecible, racional y universal.
} 
Recientemente, sin embargo, esta interpretación ha sido puesta en tela de juicio por autores menos interesados en la descalificación pura y simple del derecho colonial que en la comprensión de sus funciones y de su lógica interna ${ }^{8}$ Esta visión interpretativa del derecho Indiano pone de presente, ante todo, el carácter de los destinatarios de las normas. La sociedad colonial estaba fundada en una concepción orgánica y católica, en la cual poca cabida tenían las nociones de individuo o de derechos. Dicha concepción favorecía las relaciones jerárquicas, las prerrogativas y el poder fundado en la autoridad. A falta de individuos, en el sentido moderno, había corporaciones que detentaban lo esencial del poder político, moral y económico.

En el ámbito jurídico se hacía la distinción entre justicia y derechos, en acuerdo con la diferencia establecida por el Derecho Romano entre ius y lex. La justificación esencial del derecho era la realización de la justicia, siendo la ley un mero instrumento en la búsqueda de este propósito. La primera función del rey era la de administrar justicia.

Con el paso del tiempo la palabra derecho y la palabra ius se utilizaron como sinónimos en contraste con las leyes. El juez colonial cumplía una función primordial en este esquema pre-positivista. En efecto, en una situación de precariedad del derecho escrito, debida a la novedad de las circunstancias coloniales y a la dispersión e incomunicación extremas entre las poblaciones ${ }^{9}$, las audiencias y demás instancias judiciales cumplían un papel integrador y legitimador de gran importancia. C.H. Haring, considera que las audiencias fueron las instituciones más importantes del gobierno español en las Indias, mucho más que sus similares cancillerías en España (Haring 1947). A través de la flexibilización de los contenidos jurídicos, las audiencias lograron conciliar la validez hispánica del derecho indiano y el principio de autoridad real, con las necesidades y los intereses propios de la sociedad colonial. La discreción judicial conocida como arbitrio judicial,

\footnotetext{
${ }^{8}$ Sobre este tema los historiadores se dividen en dos tendencias que se conocen como la de la "leyenda negra", en un caso, y la de la "leyenda dorada", en el otro. La primera incluye a los historiadores que sostienen que la institución de la colonia trajo innumerables beneficios para el derecho y las prácticas sociales americanas, y que así mismo, el gobierno español se caracterizó por su rectitud administrativa hacia los nativos de las indias (Véase, por ejemplo (Ots Capdequí 1967; Díaz López 1989). La segunda incluye a quienes ponen el acento en la marcada desobediencia legal que se generó en la colonia y en las arbitrariedades de las autoridades locales (Véase, Góngora 1951).

${ }^{9}$ El desconocimiento de la realidad americana - dice Tao Anzoátegui - y de sus problemas obligó, al rey y al consejo, como es sabido, a legislar en base a las informaciones obtenidas, las que generalmente eran deficientes para adquirir un conocimiento cabal de aquella realidad (...) A ello se sumaba lo heterogéneo de la vida indiana, que impedía reducir a reglas geerales el gobierno de esas vastísimas tierras" (Tau Anzoátegui 1992)
} 
fue el mecanismo legal que permitió adaptar la legislación a las necesidades e intereses locales de tal manera que se evitaran las decisiones irrazonables ${ }^{10}$. Para lograr este propósito era indispensable que la costumbre y la equidad fuesen fuentes primordiales del derecho aplicado por los jueces y por la administración ${ }^{11}$.

Así pues el derecho creado en la América Hispánica estuvo marcado por las condiciones específicas de estos territorios. Entre ellas sobresalen su lejanía respecto de la metrópoli, la diferenciación e incomunicación entre las localidades coloniales y la existencia de una visión social dominada el organicismo católica a partir de la cual se favorecía el corporatismo, jerarquización. Bajo estas condiciones se creó un tipo específico de derecho que podemos caracterizar como flexible o dúctil.

Para los historiadores clásicos el derecho indiano era esencialmente autoritario e ineficaz. Sin embargo ambas nociones - autoritarismo e ineficacia - son complejas y requieren de explicaciones que pongan de presente sus matices. En primer lugar, respecto de la ineficacia, el ordenamiento jurídico indiano tenía grandes dificultades para permear y determinar la realidad social colonial y en este sentido puede decirse que era ineficaz. Sin embargo es conveniente diferenciar varios tipos de normas dentro del ordenamiento colonial. Siguiendo a lo dicho por Victor Anzoategui, podemos distinguir tres tipos de normas (Tau Anzoátegui 1992:12). Las primeras comprendían aquellas disposiciones emanadas en España del Consejo de Indias o en el siglo XVIII de la Secretaría de despacho. En segundo lugar estaban las normas recogidas en compilaciones o cedularios, tales como la Recopilación oficial de 1680. Finalmente, estaban las disposiciones dadas en América por los virreyes, las audiencias, los gobernadores, alcaldes, cabildos etc., conocidas como derecho indiano criollo. Es sólo en relación con los dos primeros tipos de normas que podemos hablar de notable ineficacia del Derecho Indiano. Ahora bien, el atributo de ineficacia tiene sentido desde una perspectiva estática, a partir de la cual se constata una enorme brecha entre lo prescrito por el derecho producido en España y el derecho aplicado en los territorios coloniales. Desde una visión dinámica, en cambio, la ineficacia ya no aparece tan clara si se tiene en cuenta que lo que había en el mediano y largo plazo era una adaptación y acomodamiento del derecho indiano criollo a la realidad social y política reinante.

\footnotetext{
${ }^{10}$ En la recopilación de Indias se establecía que las normas reales debían ser obedecidas, "salvo siendo el negocio de calidad, que de su conocimiento se siguiera escándalo conocido , o daño irreparable,...” Véase Recopilación de indias 2.1.22; Nueva Recopilación de indias 4.14.2 Novísima Recopilación 3.4.4. Partidas 3.18.29.

${ }^{11}$ Sobre la importancia de la costumbre en el derecho indiano véase (Tau Anzoátegui 1970).
} 
En cuanto al autoritarismo, el derecho indiano era la expresión jurídica de un régimen político fundado en la superioridad española y católica sobre la voluntad individual o colectiva de los súbditos americanos. En este sentido el calificativo de autoritario no parece irle mal. Por algo se trataba de un imperio. Sin embargo, desde el punto de vista colonial, o interno, las cosas parecen más complejas. En primer lugar, según la axiología jurídica iusnaturalista que fue impuesta en las Indias y que tuvo expresión en innumerables textos de doctrina y legislación desde los pioneros de San Isidro de Sevilla hasta los de Santo Tomás de Aquino, pasando por las Siete Partidas de Alfonso el Sabio, las normas del derecho debían estar fundadas en la razón y el bien común o de lo contrario perdían su naturaleza. ${ }^{12} \mathrm{El}$ derecho debía ser justo para que fuera derecho. Esta dependencia de la validez jurídica respecto de los contenidos justos, creó en los jueces y administradores locales un tipo de práctica jurídica favorable a la interpretación y adaptación del derecho. La fórmula "se obedece pero no se cumple" ilustra bien esta práctica ${ }^{13}$, que sin duda estaba comandada por los intereses y la visión del mundo de una pequeña élite gobernante ligada al poder español y eclesiástico de la época, y en tal sentido el autoritarismo era evidente; sin embargo, el hecho de que dicha élite debiera dar razones de buen gobierno para obtener el cumplimiento por parte de los súbditos creaba límites al ejercicio arbitrario del poder, tanto más importantes cuanto dicha élite gobernante se encontraba con frecuencia escindida a causa de intereses regionales y de clase.

La concepción jurídica según la cual el derecho escrito o positivo es sólo un primer paso en la definición del derecho aplicado, lo cual se logra luego de un proceso de interpretación, evaluación y adaptación de sus contenidos a las circunstancias específicas en las que se aplica, todo ello en unión con la conciencia popular de que dicha interpretación y adaptación se hacía en acuerdo con los intereses de la élite política dominante, fue creando a través de los siglos una cultura del uso instrumental del derecho, no sólo por parte de los ciudadanos, sino también de los gobernantes. El derecho es así flexibilizado y adaptado para servir a fines privados y públicos.

\footnotetext{
${ }^{12}$ Según San Isidro de Sevilla la ley debía ser honesta, justa, posible, conforme a la naturaleza y a las costumbres del país, conveniente al tiempo, necesaria, útil y manifiesta. Por Tau Anzoáteguui. Por su parte, según Santo Tomás de Aquino la ley "es una ordenación racional al bien común, promulgada por autoridad que tiene a su cargo el cuidado de la comunidad". Citados por Tao Anzoátegui (Tau Anzoátegui 1992). Vease igualmente (Uprimny 1953)

${ }^{13}$ La posibilidad de invocar el incumplimiento de las normas a través de la fórmula "se obedece pero no se cumple” empezó a languidecer con el advenimiento del absolutismo en la segunda mitad del siglo XVIII (Tau Anzoátegui 1992)
} 
En condiciones de precariedad hegemónica del poder político, como las que caracterizaron a los gobiernos del siglo XIX en casi toda América Latina, esta cultura se alimentaba ampliamente de razones ligadas a la ilegitimidad del poder político para obstaculizar los intentos de construcción de un estado de derecho fundado en una concepción jurídica positivista. Incluso la Iglesia católica, debido a su inescindible maridaje con el poder político se veía afectada por esta actitud de desconfianza y recelo frente a la autoridad española y a sus normas. "...el ser católico - dice Lybch - no implicaba tener una intensa convicción de lealtad hacia la iglesia: liberales y anticlericales eran nominalmente católicos y solían acatar sus normas prácticas, más que la religión como tal" (Lynch 1987)

\section{Las repúblicas}

La independencia de España trajo consigo cambios radicales en la simbología jurídica y política. La ilustración impuso una visión del mundo contraria al organicismo social, católico y jerarquizado y favorable a la igualdad formal y al individualismo. Pero tales cambios discursivos no trajeron consigo las transformaciones radicales de las relaciones sociales y de poder, que pretendieron los primeros historiadores de la independencia. Los cambios normativos no produjeron una realidad jurídico-política completamente nueva; más bien se adaptaron y acomodaron a las necesidades e intereses coloniales de manera parecida a como el derecho indiano había logrado conciliar los contenidos jurídicos españoles con las necesidades e intereses coloniales.

$\mathrm{Al}$ momento de la independencia era notable la falta de experiencia política y administrativa de las colonias hispánicas ${ }^{14}$. Esta carencia favoreció la adopción de modelos de organización política provenientes de otras revoluciones y determinó una especie de hipercentralidad del tema constitucional en el debate político ${ }^{15}$ a partir del cual se instauró un nuevo tipo de maridaje entre política y derecho. El debate constitucional, sin embargo, no fue un debate puramente técnico sobre diseño institucional. Sus contenidos estuvieron altamente politizados y alimentados por una amplia oferta de ideolo-

\footnotetext{
${ }^{14}$ Durante la Dinastía de los Borbón en el siglo XVIII, por ejemplo, los criollos estaban excluidos de la administración de los asuntos públicos. A ello contribuyó el hecho de que no existía una política pública de dirección y unidad, sino más bien una concepción de empresa privada, ajena a directrices y políticas generales de unificación (Góngora 1951).

15 "El constitucionalismo — dice Javier Ocampo López- es otro de los fenómenos históricos que encontramos en la coyuntura de la independencia. Se presenta como aquella necesidad de organizar jurídicamente un Estado y adoptar la forma más conveniente de gobierno para el nuevo Estado independiente. En el Nuevo Reino de Granada, en solo dos años -1811-
} 
gías. Entre ellos estaba, desde luego, la ilustración. Sus ideas penetraron en el mundo colonial, por diversas vías y en distintos contextos (Romero 2001), algunas veces divulgadas por pensadores españoles, otras veces por próceres de la independencia que hicieron viajes a Europa ${ }^{16}$. Obras de autores tales como Diderot, Dálembert, Voltaire, Rousseau, Locke y Hobbes fueron leídas con relativa libertad en todo el continente y de manera particular en México, Perú y la Nueva Granada ${ }^{17}$. Los acontecimientos revolucionarios de Francia y Estados Unidos de finales del siglo XVIII confirmaron la fuerza política de las ideas de la ilustración y por ello tuvieron gran incidencia en la ideología revolucionaria latinoamericana ${ }^{18}$.

1812 - se presentan seis constituciones: la Carta constitucional monárquico-republicana de Cundinamarca (marzo 3 de 1811); el acta de la federación de las Provincias Unidas de la Nueva Granada (27 de noviembre de 1811); la Constitución de la República de Tunja (diciembre 9 de 1811); la Constitución de la República de Cundinamarca (17 de abril de 1812) y la Constitución del Estado de Cartagena de Indias (junio 14 de 1812)" (Ocampo Lopez 1983). Véase igualmente José Luis Romero quien sostiene que "el constitucionalismo fue casi una obsesión desde el primer momento. Sin que se pudieran establecer principios válidos de representatividad, se convocaron por todas partes congresos que debían asumir la soberanía de la nueva nación y sancionar la carta constitucional que, de arriba abajo, moldearía la nueva sociedad. Los principios parecían sólidos, indiscutibles, universales. Pocas opiniones los objetaban. Solo los contradecía la realidad social y económica, que desbordaba los marcos doctrinarios con sus exigencias concretas, originales y conflictivas (Romero 2001)

${ }^{16}$ En una carta enviada al general Santander desde Arequipa el 20 de mayo de 1825, el libertador Simón Bolívar le dice lo siguiente: "Ciertamente que no aprendí ni la filosofía de Aristóteles, ni los códigos del crimen y del error; pero puede ser que Mr. De Mollien no haya estudiado tanto como yo a Locke, Condillac, Bufón, Dalambert, Helvetius, Montesquieu, Mably, Filangieri, Lalande, Rousseau, Voltaire, Rollin, Berthot y todos los clásicos de la antigüedad, así filósofos, historiadores, oradores y poetas” (Bolívar 1979). Sobre la influencia de las ideas de Rousseau en Simón Bolívar y Mariano Moreno véase (Lewin 1967).

${ }^{17}$ Admiración especial despertaba Rousseau y su concepto de soberanía popular Mariano Moreno editó en 1810 el Contrato Social de Rousseau con la intensión de difundir las ideas emancipatorias entre los jóvenes americanos.

${ }^{18}$ La interpretación más extendida sobre los procesos emancipatorios en América hispánica resaltan por igual aquellas doctrinas políticas provenientes de los Estados Unidos y de Francia. Entre una amplísima bibliografía véase, por ejemplo, (Maniquis 1989); (Ortiz 1960); (Robertson 1939); Basterra y Zabala (Basterra y Zabala 1970); (Carrera Damas 1971); (Gómez Hoyos 1962); (Romero 1985); (Samper 1969); (Tejada 1955); (Uprimny 1971); (Pérez 1989); (Ruiz 1989). En cuanto a la influencia de la revolución francesa de 1789 en la mentalidad política popular, ver (Aguilera 1998). Otros análisis resaltan la influencia de las ideas políticas españolas: (Aguilera 1960), quien no sólo señala tal influencia peninsular sino que la enaltece; (Jaramillo Uribe 1996). Para la revolución americana véase (Bushnell 1976); (Rodríguez 1976); (Irazábal 1939). Algunos estudios hacen una exposición tanto de las ideas francesas y norteamericanas como de las españolas: (Lynch 1987); (Ocampo Lopez 1983). 
Sin embargo, la recepción de estas ideas revolucionarias no se hizo de manera directa, ni homogénea ni pacífica. En ello influyeron tanto las condiciones materiales o económicas, como las condiciones ideológicas o políticas que existían al momento de la recepción de tales ideas. Este complejo entramado de condiciones hizo que las ideas de la ilustración terminaron operando en complejas combinaciones con otros idearios políticos.

Respecto de las condiciones ideológicas locales, la recepción del pensamiento de la Ilustración se produjo a través del filtro impuesto por dos visiones del mundo colonial contrapuestas. Una de ellos era el llamado "americanismo" engendrado a finales del siglo XVIII y que consistía en una especie de nacionalismo continental de tipo cultural, no político, difundido, entre otros, por los jesuitas expulsados en 1767, quienes exaltaban la riqueza natural cultural del continente americano $^{19}$. El americanismo no era ni mucho menos un pensamiento revolucionario pero preparó las revoluciones. Según Hans J. König " La adhesión sentimental a América se convirtió en un concepto cada vez más político, de manera que no solo expresaba un "ser diferente", una "otredad" frente a España, sino que también comprendía un aspecto de orientación y acción: la superación del status colonial, con el objetivo de conseguir la libertad y la independencia política (König 1994:)

De otra parte, las ideas de la Ilustración fueron atenuadas y moldeadas por el pensamiento conservador, católico y autoritario que prevalecía en las colonias hispánicas de finales del XVIII y que se justificaba bajo la consigna real de introducir orden y cristiandad en comunidades indígenas más o menos indómitas ${ }^{20}$. La tradición conservadora no sólo dio lugar a la justificación pura y simple del autoritarismo, sino también a discursos políticos híbridos destinados a la defensa de la monarquía. Este es el caso del escritor español Gaspar Melchor de Jovellanos, quien defendía la idea de soberanía indivisible, al estilo Rousseau, para justificar la autoridad del rey ${ }^{21}$.

Pero el pensamiento autoritario colonial no siempre tenía origen conservador; en ocasiones se fundaba en la necesidad de producir una rápida transformación igualitaria desde el Estado. Así por ejemplo, de las ideas roussonianas, casi

\footnotetext{
${ }^{19}$ Ver por ejemplo las Lettres aux Espagnols-Americains del jesuita peruano Juan Pablo Viscardo, publicada en 1799.

20 "La ilustración — dice John Lynch— de ningún modo era universal en América, ni tampoco sobrevivió intacta una vez que se implantó allí, puesto que su expansión, mermada por el conservadurismo y limitada por la tradición, fue escasa" (Lynch 1987)

${ }^{21} \mathrm{Al}$ respecto véase (Romero 1985).
} 
metafísicas, de "volonté générale" y "soberanía popular" surgieron dos tipos de planteamientos políticos revolucionarios. Por un lado estuvieron aquellos líderes políticos radicales que, muy influenciados por el pensamiento jacobino, defendían la idea de que todo el poder debía ser entregado al pueblo y que una nueva era social y política debía ser construida a partir del derrumbe del ancien régime ${ }^{22}$. Otros, en cambio, estimaban que la interpretación radical de la soberanía popular era inadecuada dadas las condiciones de atraso, marginalidad e inexperiencia política del pueblo y que, en consecuencia, debería crearse un Estado fuerte, una especie de Estado de excepción, que pudiera facilitar la transición hacia una verdadera democracia ${ }^{23}$. La lectura de los autores de la Ilustración con frecuencia sirvió para legitimar un cierto despotismo ilustrado que se justificaba y causaba al mismo tiempo en la ausencia de una modernidad consolidada (Jaramillo Vélez 1998); (Jaramillo Uribe 1996). Por esta vía se fomentó el caudillismo ${ }^{24}$ y el voluntarismo político cuya manifestación más reciente se encuentra en los regímenes llamados populistas (Touraine 1988)

Pero la fuerza de las ideas americanistas y conservadoras que dominaban en los territorios coloniales de finales del siglo XIX no es suficiente para explicar el relativo fracaso de la empresa revolucionaria en esta materia. También hay que tener en cuenta que tales ideas favorecían la permanencia de condiciones materiales de distribución de la riqueza y de diferenciación social entre clases que subsistieron no obstante las pretensiones igualitaristas proclamadas por las revoluciones. En primer lugar, la recepción y difusión de las ideas emancipadoras se limitó, por lo menos en el inicio de los acontecimientos independentistas, a un pequeño grupo de criollos blancos e intelectuales ubicados en los principales centros urbanos: Bogotá, México, Caracas, Lima, entre otros pocos. Esto es especialmente significativo si se tiene en cuenta que, según Alexander von Humboldt, a finales del siglo XVIII de los casi 19 millones de habitantes que tenía el continente sólo algo más de tres millones eran blancos. El resto de la población era pobre e iletrada y no fue parte activa del proceso de recepción y discu-

\footnotetext{
22 Véase por ejemplo el discurso denominado "Plan político" de José María Morelos en 1813 en donde defiende la idea de destruir todo lo que tenga relación con el antiguo régimen, incluida la poca industria existente. Véase igualmente la "Proclama" del chileno Camilo Henríquez de 1811; igualmente los discursos del argentino Bernardo de Monteagudo.

${ }^{23}$ Véase, por ejemplo, el Manifiesto de Cartagena de Simón Bolívar; así mismo el discurso de Antonio Nariño en la apertura del Colegio Electoral de Cundinamarca el 13 de junio de 1813. ${ }^{24}$ Para Lynch, "el caudillo era un jefe regional que derivaba su poder del control que tenía sobre los recursos locales, especialmente las haciendas lo que le otorgaba acceso a hombres y provisiones. El caudillismo clásico adoptaba la forma de bandas armadas regidas por relaciones patrón-cliente, unidos por los lazos personales de dominio y sumisión y por el deseo común de obtener riqueza mediante el uso de las armas" (Lynch 1987).
} 
sión de estas ideas. Para el caso colombiano, según McFarlane, quien se basa en datos de un censo realizado entre 1778 y 1780, la Nueva Granada tenía una población de 800.000 habitantes. La mayor parte de la gente vivía en el campo, concentrada en el interior de rústicos municipios con poblaciones entre 5.000 y 15.000 personas. Bogotá, a fines del siglo XVIII tenía unos 20.000 habitantes ${ }^{25}$. Detrás del igualitarismo formal proclamado por los próceres de la independencia permanecía una división del trabajo entre clases sociales : mientras los criollos descendientes de España asumían los nuevos cargos públicos, los indios y los negros seguían siendo la fuerza animal que cavaba minas, cultivaba haciendas y plantaciones, construía caminos, levantaba iglesias y edificios públicos (Nuñez, 2000:202).

Debido a esta división entre clases, la alianza entre las elites criollas y clases subalternas contra el enemigo español era más simbólica y coyuntural que otra cosa. Entre los intereses de, por un lado, los criollos que difundían el pensamiento de la Ilustración para separarse de España y, por el otro, el pueblo raso que utilizaba los símbolos emancipadores de dicho pensamiento para manifestar su rebeldía contra los españoles opresores, había muy poca unidad. Esto explica el hecho de que las proclamaciones grandilocuentes de las constituciones sobre igualdad y ciudadanía coexistieran con instituciones coloniales de orden legal ${ }^{26}$ como por ejemplo la esclavitud, la encomienda y el voto cencitario ${ }^{27}$

\footnotetext{
${ }^{25}$ La población estaba dividida entre blancos, negros, indios y "libres de todos colores". El grupo más grande era el de los libres o mestizos. En 1780, gente con mezcla racial constituía casi la mitad de la población (46\%). La mayoría de los demás estaban clasificados bien como blancos (26\%) o indios (20\%), seguidos por una minoría sustancial de un $(8 \%)$ de esclavos negros (Mcfarlane 1997).

${ }^{26} \mathrm{El}$ continuismo de instituciones coloniales fue una estrategia ampliamente usada durante la república. Esta garantizaba en algunas ocasiones, no solo, una continuidad de las formas económicas de explotación, sino que en otras, fue utilizado sagazmente como una herramienta populista de legitimación por los próceres de la independencia para conseguir aprobación popular. Un detallado estudio de este fenómeno puede verse en (Ortiz Caballero 1989).

${ }^{27} \mathrm{Al}$ respecto, relata José Luis Romero "Vulnerar el principio de la servidumbre indígena o de la esclavitud negra significaba introducir una nueva actitud con respecto a la mano de obra barata sobre la que se basaba la economía americana. Y, en efecto, el movimiento emancipador tuvo también contenidos económicos"(Romero 2001). Sobre el sistema electoral Ciriza sostiene que "La consideración de los hombres como si fueran iguales implicarían un tratamiento formal de la igualdad que invisbilizaría las formas de exclusión, no sólo de quienes no podían cumplir con los requisitos económicos de la ciudadanía por no ejercer oficio libre, o carecer de propiedad, sino de las mujeres, para las cuales se contemplaría una particular forma de exclusión incluyente: el contrato sexual" (Ciriza 2000)
} 
Pero, de nuevo, las condiciones materiales que subyacen a esta estructura de clases son también insuficientes para reducir la empresa revolucionaria a un simple mecanismo de manipulación política. Los ideales revolucionarios no sólo configuraron un nuevo tipo de Estado con nuevas reglas, nuevos actores y nuevas relaciones de poder, sino que fortalecieron la conciencia popular de rebeldía y oposición a la autoridad española ${ }^{28}$ (Aguilera 1998). La contundencia y simplicidad de los principios políticos que venían de Francia — sobre todo aquéllos ligados a las ideas de soberanía popular e igualdad - respondía bien a un malestar popular, muchas veces cercano al odio, y a la necesidad de satisfacer una pulsión de retaliación, represada durante siglos, contra el poder blanco y español. El ideario revolucionario sirvió para reconstituir la conciencia legal y política no sólo de las clases dominantes sino también de las subalternas y para configurar un nuevo campo de relaciones políticas entre dichas clases.

En síntesis, el nuevo campo político instaurado por la independencia estaba menos determinado por la adopción pura y simple de los idearios y de las prácticas provenientes de las revoluciones que habían tenido lugar en Francia y Estados Unidos que por la combinación intrincada de estos discursos y prácticas con los discursos y las prácticas que prevalecían en los territorios coloniales a principios del siglo XIX y que he denominado condiciones ideológicas las cuales eran, en buena parte, expresión de ciertas condiciones materiales de dominación económica.

El hecho que me interesa resaltar por ahora es el siguiente: la confluencia de estos discursos y prácticas dio lugar a la configuración, por un lado, de una fuerte disociación entre postulados jurídicos fundamentales y realidad social e institucional similar a la que existía en la colonia entre el derecho castellano y el derecho indiano y, por el otro, a una utilización amañada y con frecuencia autoritaria de los contenidos jurídicos, que también evoca lo sucedido con el derecho indiano.

La brecha entre derecho y realidad social estuvo ésta vez favorecida la pretensión universalista y racional de las ideas de la ilustración. Estas ideas dieron lugar a un debate esencialmente ideológico y abstracto entre intelectuales afrancesados que por lo general tenían un franco desprecio por

\footnotetext{
28 “ Dos serán los signos de la revolución - afirma Alejandra Ciriza-. Por una parte, ellas se realizan en nombre de la libertad, libertad para los americanos respecto de la metrópoli, libertad de comercio e industria, libertad de los esclavos y ruptura de las relaciones serviles, libertad de conciencia; por la otra, el movimiento revolucionario proclamará, al menos durante el ciclo ascendente de la revolución, el derecho a la igualdad." (Ciriza 2000)
} 
los problemas de la implementación o de la eficacia de las ideas políticas ${ }^{29}$. En una actitud muy propia de los revolucionarios de los primeros años de la Revolución Francesa se pensaba que una vez encontrada la "verdad política", el resto vendría por añadidura ${ }^{30}$. A esto se agregaba el hecho de que las exigencias de la Independencia no daban tregua y que la necesidad de un discurso con vocación nacional e institucionalmente eficaz era apremiante. Aquí también la simplicidad y contundencia del ideario revolucionario francés facilitó su utilización política: los conceptos de "voluntad general", "soberanía", "derechos del hombre", "ley" y "ciudadanía" fueron utilizados por los hacedores de la Independencia para construir la nación a partir de los fragmentos dejados de la mano de los españoles ${ }^{31}$. Había un cierto consenso en la mayor admiración que producían las revoluciones inglesa y americana, pero ninguno de los idearios políticos provenientes de estas revoluciones tuvo tanto impacto como el ideario francés. Esto se debe quizás al carácter particular, histórico y en buena parte intransferible de los debates anglosajones. Sir Edward Coke fue tan importante para el constitucionalismo moderno como Rousseau o Sieyes, sin embargo era muy difícil trasladar sus ideas sobre el common law al debate constitucional latinoamericano. Antonio Nariño tradujo la Declaración de los Derechos del Hombre y del Ciudadano y no el Bill of Rights inglés de 1689 ni la Declaración de Independencia Americana de 1776 porque el tenor universalista y racionalista de los enunciados de la primera estaba llamado a tener mucho más impacto político y sentido revolucionario que los enunciados en buena parte locales e históricos de los documentos anglosajones.

\footnotetext{
29 "En los grandes debates alrededor de los destinos públicos — dice Jaramillo Vélez— se constata desde un principio el divorcio entre el postulado acogido en la Carta Magna, en los textos, en los tratados de derecho público, en las proclamas, y la realidad o la práctica social, impregnadas por la inercia de una sociedad señorial que se resistía por todos los medios a los esfuerzos de la modernización". (Jaramillo Vélez 1998).

${ }^{30}$ Tocqueville criticaba esta mistificación de las grandes ideas y este desprecio por los asuntos de gobierno, muy propios de la Revolución Francesa, en los siguientes términos "La misma condición de estos escritores les predisponía a abrazar las teorías generales y abstractas en materia de gobierno y a confiar en ellas ciegamente. Viviendo tan alejados de la práctica, ninguna experiencia venía a moderar su natural ardor..." (Tocqueville 1972) (1998:223). Críticas similares contra el racionalismo político están presentes en (Burke 1912) entre otros.

${ }^{31}$ Estos principios eran, como se dijo antes, similares a los recogidos por la tradición española y haciendo que la recepción fuera menos dramática que con otras ideologías (Uprimny 1953).
} 
De otra parte la selección de los modelos constitucionales y de sus respaldos ideológicos en América hispánica estaba más fundada en las necesidades de legitimación política que en su efectividad instrumental (Ortiz Caballero 1989). Los próceres de la independencia se vieron obligados a utilizar el derecho como herramienta de construcción de la nación y de la ciudadanía. La ausencia de una participación política organizada, por ejemplo a través de partidos políticos fuertes y con arraigo social, impuso, desde los inicios del período republicano un traslado de la función política de articulación social propia del sistema político, al discurso jurídico y más concretamente al diseño constitucional. ${ }^{32}$ Esta práctica sigue latente en América Latina: el recurso a las reformas constitucionales es todavía una solución política frecuente para resolver las deficiencias de una democracia representativa fuerte ${ }^{33}$.

Los acuerdos jurídicos expresados en constituciones y códigos tenía como aliciente mayor la superación ideológica del Ancien regime y del enemigo español pero sus términos, demasiado generales y abstractos, ocultaban diferencias culturales y económicas que se resistían al cambio, lo cual se traducía en una disociación palmaria entre contenidos jurídicos y realidades sociales y económicas ${ }^{34}$. Pero la incapacidad del nuevo derecho republicano para permear el tejido social ${ }^{35}$ no era un fenómeno nuevo. Como ya fue explicado, el derecho

\footnotetext{
${ }^{32}$ Según Romero durante las primeras décadas de la independencia "Todos parecieron creer que una sabia constitución era el recurso supremo para encauzar la nueva vida de las sociedades, y solo discrepaban los que pensaban que debía ser meticulosa y casuística con los que creían que debía ser sencilla y limitada a las grandes líneas de organización del estado. Así, frente al constitucionalismo, se fue constituyendo poco a poco una mentalidad política pragmática que debía terminar justificando la dictadura de quien tuviera la fuerza y autoridad para asegurar el orden y la paz resolviendo autoritariamente los conflictos concretos surgidos de los intereses y las expectativas en pugna (Romero 2001)

${ }^{33}$ Algo diferente sucedió en el proceso de independencia de las 13 colonias inglesas en el norte de América. El hecho de que los ingleses hubiesen permitido una cierta autonomía política de las colonias (Jacobson, 1932), ligado a una cierta homogeneidad cultural y económica de los colonos, favoreció el trámite pacífico de las tensiones políticas propias del proceso revolucionario. Mientras en el sur del continente había enormes dificultades para impedir, tanto el resurgimiento de las formas autoritarias de poder como la caída en la guerra civil, en el norte se consolidaba un complejo pacto social de democracia restringida por procedimientos institucionales de corte aristocrático (Jacobson 1932).

${ }^{34}$ Esto, de otra parte, obedece a un fenómeno más general: mientras más heterogéneo y jerarquizado es un conglomerado social, más general e ideológico es el contenido de un eventual contrato social o acuerdo constitucional; esto se origina en la necesidad política de abarcar —u ocultar — las diferencias sociales y políticas en un mismo discurso.

$35 \mathrm{Si}$ algo es específico a las revoluciones latinoamericanas es su incapacidad para traducir contenidos ideológicos y jurídicos en cambios sociales (Romero 2001), (Levine 1956).
} 
producido en España para las colonias pocas veces era interpretado y aplicado de la manera como había sido previsto en la metrópoli. Sin embargo, la manera como operó esta brecha entre derecho y realidad difería en ambos períodos.

En América Latina el pluralismo jurídico se ha impuesto tozudamente y desde siempre a las proclamaciones jurídicas. En tiempos de la colonia el pluralismo jurídico fue legalmente rechazado. Así se estableció desde finales del siglo XVI con fundamento en una política de asimilación cultural y dominación política de los pueblos indígenas. ${ }^{36} \mathrm{La}$ exclusión del pluralismo de jure, sin embargo, dio lugar a un pluralismo de facto ${ }^{37}$ : múltiples órdenes legales y códigos de conducta asociados a clases, regiones y culturas coexistieron no obstante las pretensiones españolas de unificación jurídica ${ }^{38}$. Sin embargo, la coexistencia de órdenes normativos diferenciados tenía un cierto reconocimiento legal a través de la aceptación y promoción que el derecho indiano hacía de la costumbre jurídica. Esto hizo posible que el derecho indiano perdurara como mecanismo importante del poder colonial español, no obstante su ineficacia y su autoritarismo. Con el advenimiento de la república, la costumbre fue prácticamente anulada por la ley codificada, única expresión válida de la voluntad democrática y soberana. Según el ideario revolucionario, el reconocimiento jurídico de la costumbre era el mecanismo mediante el cual se entronizaban los privilegios y el autoritarismo colonial. Los ideólogos de las repúblicas veían en la codificación un remedio para estos problemas y un instrumento para crear un nuevo ordenamiento fundado en la igualdad ciudadana. Sin embargo, estas intenciones no dieron al traste con la heterogeneidad social que sustentaba el pluralismo jurídico y por el contrario, debido a la decisión de excluir la costumbre jurídica, contribuyeron a la disociación entre normas y hechos.

\footnotetext{
${ }^{36}$ Esta fue la época en la que el poderoso vice-rey Toledo decidió terminar en los países andinos la coexistencia de estructuras legales indígenas y españolas y reemplazar dicha coexistencia por una imposición plena del derecho español

${ }^{37}$ En los territories coloniales del Asia y Africa, fue generalmente aceptado el pluralismo de jure. Most of the influential research-based formulations of legal pluralism have not been based on Latin American examples (see, e.g., (Abel 1982); (Benda-Beckman 1979; BendaBeckman 1992); (Hooker 1975); (Moore 1986; Moore 1978); (Pospisil 1971); (Snyder 1981).

${ }^{38}$ En las sociedades semitradicionales - dice Roberto Da Matta - "operan muchos códigos de conducta de manera simultánea, sin competir entre ellos sino complementándose..... El resultado es .. una multiplicidad de códigos y ejes clasificatorios que dan al sistema una alta complejidad y dinamismo peculiar" (Da Matta 1987). Stern (1982) ha mostrado cómo durante la colonia los indígenas de los Andes, mantenían estructuras legales alternativas no obstante la imposición de adaptar sus costumbre a las nuevas normas españolas.
} 


\section{La codificación}

La identificación del derecho con la ley es un legado de la Revolución Francesa y de su influencia en la inspiración del Código de Napoleon de 1803. Los seis primeros artículos del título preliminar de este código contienen todo un paradigma jurídico político que identifica derecho y ley ${ }^{39}$. Tal identificación no es explícita, pero se deduce claramente de la redacción de los artículos, los cuales desarrollan un concepto de derecho que sólo tiene por fuente la ley. ${ }^{40} \mathrm{Al}$ llegar a España el código de Napoleón choca con una concepción tradicional que no sólo establecía la pluralidad de fuentes jurídicas -legislación, costumbre, jurisprudencia - sino que desconocía la existencia de fronteras claras entre religión e interpretación de aquellas fuentes. No obstante el código civil francés, con su vocación universalista y racional fue objeto de una recepción entusiasta por parte de juristas simpatizantes del proyecto modernista francés. Sin embargo, este entusiasmo no se ve del todo reflejado en la constitución de Cádiz de 1812, la cual, si bien en algunos de sus apartes parece identificar el derecho con la ley prefiere la adopción de una concepción constitucionalizada de los derechos, idea esta que provenía en parte de la legislación de Haití, en la cual el elemento central no era la ley sino la protección de los derechos individuales ${ }^{41}$ y por supuesto de la revolución estadounidense de 1776.

En estas primeras batallas entre codificación y derechos será la primera la que saldrá airosa tanto en España como en América Latina. En el nuevo continente la influencia francesa se inicia con el código civil de Oaxaca que se promulga por partes entre 1827 y 1829 y cuyo título preliminar es una versión del código de Napoleón ${ }^{42}$. Le siguen los códigos de Bolivia (1831), Costa Rica (1841) y República Dominicana (1845). Pero es el código civil chileno de 1855 el más representativo e influyente de las compilaciones civiles que se hicieron durante la segunda mitad del siglo XIX en América

\footnotetext{
39 (Clavero 1994: )

${ }^{40} \mathrm{El}$ artículo cuarto dice así: "El juez que se niegue a juzgar, con pretexto de silencio, oscuridad o insuficiencia de la ley, podrá ser acusado como delincuente de denegación de justicia y el artículo quinto, a su turno dice: "Se apercibe a los jueces de terminar, por vía de disposición general o reglamentaria, sobre las causas que conocen

${ }^{41}$ Idem, p. 90

${ }^{42}$ Este título contiene algunas innovaciones como la que trae el artículo 8 cuando establece que todo habitante del estado está obligado a instruirse y a conocer las leyes, lo cual era una exigencia bastante onerosa en una sociedad predominantemente indígena que por lo general no leía el idioma español. Véase (Chance 1982)
} 
Latina $^{43}$. El título preliminar de este código contiene 6 secciones que desarrollan el concepto, la promulgación, los efectos, la interpretación, el entendimiento y la derogación de la ley. El derecho es aquí entendido como la ley, la cual es percibida como una declaración de la voluntad soberana que sólo puede ser interpretada por el legislador. La voluntad soberana expresada en la constitución, por una parte y la costumbre, proveniente de la realidad social, por la otra, las cuales se ubican en los dos extremos de una trilogía en donde la ley es el punto intermedio, son, en la práctica jurídica, subsumidas en la voluntad del legislador. La trilogía es simbólica, no instrumental. La costumbre es reconocida, pero únicamente cuando es remitida por la ley. De esta manera se consagra la marginalidad jurídica del Derecho Indiano y con ella el desencuentro del derecho moderno con la realidad social. La jurisprudencia, por su parte, sólo tiene validez respecto de los casos concretos a los cuales se refiere. Es cierto que el legislador decide en consonancia con la constitución, pero ésta, la constitución, es aquí una mera referencia abstracta, producto de la idea rusoniana según la cual la voluntad soberana - en este caso encarnada en el legislador ${ }^{44}$ - es la fuente de la constitución ${ }^{45}$. De esta manera el código presupone no sólo una identidad entre ley y derechos sino también entre soberano y ley. La vía constitucional queda reducida a la vía legal. Una muestra elocuente de esta subordinación constitucional se encuentra en la incorporación que hace el código civil colombiano - copiado del código de don Andres Bello - del titulo III constitucional sobre los derechos con el objeto de darles una presencia que no tenían en medio del documento constitucional. Era tan claro que la ley era la fuente de todo el derecho y que si la constitución era superior a la ley ella sólo lo era en un plano simbólico, por lo demás muy débil, que la incorporación constitucional en el código civil era la mejor manera de remediar al menos en el plano retórico la penuria de los derechos.

\footnotetext{
${ }^{43}$ Sobre su influencia en el resto del continente véase (Guzmán Brito 1982). El código fue elaborado a partir de la traducción del Código civil francés de Napoleón hecha por don Andrés Bello y contiene un estudio introductorio de Gumersido de Azcaráte. Véase (Bravo Lira; Guzmán Brito 1982).

${ }^{44}$ Rousseau no defendía el sistema de representación política y por lo tanto no exaltaba al legislador debido a que en su opinión la soberanía popular no podía ser representada. La entronización francesa del legislador es obra de Sieyes y sus seguidores.

${ }^{45}$ Es también cierto que aparecen otras fuentes tales como la costumbre, pero su alcance queda reducido a lo que la ley diga. Así, el artículo segundo dice que "La costumbre no constituye derecho sino en los casos en que la ley se remita a ella". Por su parte el artículo tercero sostiene que "las sentencias judiciales no tienen fuerza obligatoria sino respecto de las causas en que actualmente se pronunciaren".
} 
El código civil chileno de Don Andrés Bello fue adoptado casi sin modificaciones por Colombia en 1873 durante la vigencia del régimen federal ${ }^{46}$. En Colombia se estableció entonces que "la ley es una declaración de la voluntad soberana manifestada en la forma prevenida en la constitución nacional" (art.4). La costumbre, por su parte "...en ningún caso tiene fuerza contra la ley" (art. 8) y "la ignorancia de la ley no sirve de excusa" (art. 9). Un reforzamiento similar de la primacía de la ley tuvo lugar en los códigos civiles de Venezuela promulgado en 1862 así como los de Uruguay de 1868, Paraguay de 1876, Argentina de 1869 y México en 1870. Este último fue renovado con modificaciones mínimas en 1884 y 1928. Sin embargo es importante señalar que el texto de 1928, promulgado, en plena época revolucionaria, es menos enfático en la exclusión de la costumbre. Si bien el artículo 21 establece que la ignorancia de las leyes no sirve de excusa (art. 21) también consagra este sorprendente parágrafo:

“... los jueces, teniendo en cuenta el notorio atraso intelectual de algunos individuos, su apartamiento de las vías de comunicación y su miserable situación económica, podrán, si está de acuerdo el Ministerio Público, eximirlos de las sanciones en que hubieren incurrido por falta de cumplimiento de la ley que ignoraban, o de ser posible, concederles un plazo para que se cumplan; siempre que no se trate de leyes que afecten inexcusablemente al orden público"

Sin embargo este reconocimiento de la costumbre y con ella de una realidad por lo general extraña al proyecto moderno de los códigos fue una excepción en el continente. Se impuso, en cambio, un sistema de normas, valores y comportamientos elaborados bajo el supuesto de su racionalidad y universalidad y que, en consecuencia, no podían sino desconocer una realidad social heterogénea y multicultural que difícilmente se acomodaba a tales categorías normativas, empezando por la existencia de barreras linguísticas que impedían a la población indígena, muchas veces mayoritaria, acatar lo dispuesto por una élite gobernante criolla y citadina ${ }^{47}$. El consenso entre gobernantes y juristas del siglo XIX en relación con la prevalencia de la legislación tanto sobre la costumbre como sobre el principio de equidad aplicado a través de la jurisprudencia, es un fenómeno político no sólo poderoso sino también sorprendente, debido al poco peso que

\footnotetext{
${ }^{46}$ (Bravo Lira)

47Véase (Jordán Pardo 1990); (Hernández Gil 1976); (Williams 1990); (Skinner-Kleé 1954); (Gamio 1958)
} 
tuvieron las voces y los hechos que se opusieron ${ }^{48}$. Quizás ello pueda ser explicado por el hecho de que la unidad nacional y la consolidación de un principio unificador - en este caso el ideal de la ciudadanía - eran percibidos como el desafío fundamental que debían enfrentar los estados del siglo XIX en América Latina. El reconocimiento de la costumbre y de la equidad eran poco funcionales a estos propósitos. De otra parte la recepción de las ideologías jurídicas, en especial aquellas que provenían de Francia y Estados Unidos siempre se hicieron a partir de las grandes consignas políticas del momento de tal manera que se dejaba de lado el debate técnico-jurídico más específico y elaborado. Esto responde desde entonces a las necesidades de apropiación política de los discursos jurídicos que en América Latina siempre han sido percibidas como más apremiantes que en otras latitudes.

\section{Derechos y ley}

La reducción de los derechos a la ley en América Latina a partir de la recepción del código de Napoleón no fue algo natural ni fácil. En primer lugar porque tampoco había sido fácil en Francia. ${ }^{49}$ El espíritu legal de la colonia había regido demasiado tiempo y servido intereses aún demasiado fuertes como para que los designios revolucionarios pudieran cambiar la realidad jurídica de un momento a otro. Sin embargo, logro imponerse, por lo menos en los círculos burocráticos y urbanos en los que operaba el poder estatal.

Fundados en el espíritu de la Revolución Francesa, los próceres de la independencia extractaron ahora la justificación del despotismo ilustrado, ahora el llamado a la sublevación popular permanente o al radicalismo democrático. Ambos casos fueron justificados como una expresión de la

\footnotetext{
${ }^{48}$ Entre los detractores de la codificación estaba el argentino Juan Bautista Alberdi quien en 1837 publica Fragmento preliminar al estudio del derecho, Buenos Aires 1955. En cuanto a los hechos estaba no sólo el triunfo de los opositores a la codificación en los Estados Unidos sino incluso en el Estado de Luisiana en donde no obstante la influencia de la cultura francesa se daba en un mayor peso a la costumbre y a la equidad. Sobre el debate acerca de la codificación en los Estados Unidos véase (Charles 1981); (Merryman 1994); (Forkosch 1989); En este debate el jurista James Coolidge sostiene que la idea de código tiene un origen despótico, propio de aquellos países en los cuales el poder despótico, absoluto o cualificado, ha sido predominante (Carter 1884); Véase igualmente (Grossi 1991).

${ }^{49}$ El Código de Napoleón se decía depositario de una tradición que había iniciado en 1789 pero entre esta fecha y 1803 cuando el código es promulgado muchas variaciones y conflictos tuvieron lugar.
} 
"ley" y de su unión inescindible a las mayorías políticas. Se pasó así de la soberanía popular al Estado de derecho; del gobierno de Asamblea al gobierno de los códigos. La participación política fue sustituida por la representación y esta por la codificación. (Arnaud 1973). Desde entonces el derecho y la ley pasaron a ser la misma cosa en las percepciones políticas de los pobladores ${ }^{50}$. Roberto Da Marta ha ilustrado algunas de estas ideas a través de la politización que el concepto de ciudadanía tuvo en las revoluciones de América del Sur en contraste con la revolución norteamericana. Por la primera década del siglo XIX, cuando el movimiento de independencia contra España y Portugal empezó a dar sus frutos en toda América Latina, la noción de "ciudadano" traía connotaciones revolucionarias de libertad y emancipación social (Melo 1992: 90). Un proceso similar había ocurrido en Estados Unidos tres décadas antes. Sin embargo, mientras allí se consideraba que la ciudadanía estaba asociada con la defensa de derechos, particularmente con los civiles, en América Latina la ciudadanía tenía, o bien un significado político abstracto ${ }^{51}$ diseñado para crear una identidad legal artificial necesitada para conducir la revolución, o bien un significado legal muy concreto atado a la imposición de contribuciones, alistamiento, u otro tipo de deberes legales (Da Matta 1987) ${ }^{52}$. En consecuencia, la ley significó sumisión más que

${ }^{50}$ En las revoluciones inglesa y norteamericana, en cambio, la idea de los derechos individuales como límites del poder político y de la dominación fue algo esencial. Las comunidades puritanas de Nueva Inglaterra articularon sus luchas de independencia con fundamento en las ideas contractualistas de Locke a partir de las cuales los derechos del ciudadano — no la voluntad general — eran el fundamento de todo el andamiaje jurídico libertario. No sólo los derechos y la ley eran dos cosas claramente diferentes sino que se puede decir que la revolución misma de 1776 se hizo contra la idea de que las obligaciones ciudadanas y particularmente los impuestos pudieran tener alguna autonomía por fuera de los derechos. ${ }^{51}$ No sobre advertir que el concepto de ciudadanía en Rousseau está más asociado con los derechos políticos que con los derechos civiles, en contraste con Locke, para quien estos últimos son los derechos esenciales del pacto social. Locke tuvo una influencia fundamental en los debates constitucionales de la revolución norteamericana, mientras que las jóvenes repúblicas latinoamericanas recibieron una fuerte influencia de Rousseau.

52 Además de estos usos políticos, la ciudadanía era drásticamente restringida a los pudientes.

“... el que posee y reside puede llamarse ciudadano — dice un texto aparecido en el Semanario de Caracas, 23 y 30 de diciembre de 1810 (citado en Izard 1990:21) — y en los ciudadanos solamente reside la Soberanía de aquella, porque son los que se interesan en su existencia, orden y prosperidad. Los no-propietarios limitadamente tienen un derecho a ser protegidos por el Estado en razón de su obediencia a las leyes, y de su buena conducta, y a una esperanza a participar en la soberanía, cuando ayudados de su trabajo y de la fortuna se coloquen en la clase de los propietarios [...]. Pretender que todos los habitantes tengan indistintamente igual influjo político en una nación es romper los resortes de la emulación y dar motivo a que el honrado y pacífico poseedor viva continuamente amenazado de los insultos y violencias del codicioso y vagamundo, del ocioso atrevido y del malvado tunante". 
el poder de derechos. El estatus y las conexiones sociales (esto es, el capital social y económico) fueron -y aún son con frecuencia - una fuente más importante de poder y protección que el derecho ${ }^{53}$. Así, los campos jurídicos estuvieron caracterizados por la conducta estratégica de los ciudadanos en relación con los comandos legales, más que en la reivindicación ética de los derechos.

En América Latina, la mezcla estatista entre derecho y ley comienza con el lenguaje. En efecto, la lengua castellana —así como la francesa - utilizan la palabra derecho para referirse a tres cosas diferentes: al sistema de normas u ordenamiento jurídico, a los derechos de las personas y, por último, en ciertos eventos, a los impuestos conocidos como aranceles ${ }^{54}$. En lengua inglesa, en cambio, la palabra right sólo expresa la facultad de una persona de obtener ciertas prerrogativas. Durante la gesta de independencia las urgencias políticas ligadas a la necesidad de articular un discurso nacional que abarcara todas las diferencias sociales existentes afectaron dicha polisemia de tal manera que las ideas de derecho y ciudadanía dieron lugar a un desplazamiento del sentido de estos conceptos en beneficio de los referentes institucionales e ideológicos que venían de la Revolución Francesa y en detrimento de su connotación individualista y anti-poder que venían de las revoluciones estadounidense e inglesa.

Pero la confusión entre derecho y ley en la tradición jurídica creada por la Revolución Francesa es mucho más que un asunto semántico ${ }^{55}$. La unidad con-

${ }^{53}$ De acuerdo con (Nino 1989) basado en (Lipset 1986) un componente cultural importante en América Latina consiste en la resistencia de los actores del campo jurídico y de la ciudadanía en general a internalizar principios universales, basados en la competencia, en lugar de las conexiones y el estatus social. Véase también (Garrido 1993). Al respecto es ilustrativo lo dicho por Ignacio de Herrera en pleno siglo XIX : "Tampoco conviene que los togados de yndias y acesores (sic) de los virreynatos permanezcan mucho tiempo en las plazas, una triste experiencia nos ha hecho palpar que a poco se hallaban llenos de conexiones y amistades que les sirven de tropiezo a la recta administración de justicia"

${ }^{54}$ En el pasado se hablaba por ejemplo del pago "derecho de alcabala".

${ }^{55}$ Eso se aprecia en la redacción del artículo cuarto de la Constitución de 1793 en donde se dice que "la ley es la expresión libre y solemne de la voluntad general [...] ella sólo puede ordenar lo que es justo y útil a la sociedad y sólo puede prohibir lo que es perjudicial”. El concepto de ley en esta norma puede tener dos lecturas posibles; la primera es una lectura normativa a partir de la cual se entiende que la ley debe hacer lo que allí se expresa; dada la eventualidad de que la ley prohiba o permita lo perjudicial habría, o bien un derecho de rebeldía o bien un mecanismo de control del poder legislativo. Sin embargo, esta lectura no parece haber sido la que finalmente se impuso; la interpretación que resultó airosa en los debates constitucionales de 1790-1793 parece haber sido una de tipo fáctico o descriptivo según la cual la ley, siendo la expresión libre y solemne de la voluntad general, nunca se equivoca y en consecuencia ella no es otra cosa que la justicia y el bien en esencia (Blanco Valdés 1998:). 
ceptual inescindible entre ley y legitimidad creó, por la fuerza de los hechos, una cultura jurídica fundada en la convicción ciudadana de que dicha unidad enmascaraba el verdadero corazón de la dominación ${ }^{56}$.

En contraste con la tradición del rule of law, según la cual la democracia presupone libertad y constitución, en América Latina las élites políticas invirtieron este postulado a la manera francesa: la libertad presuponía soberanía y voluntad popular, lo cual se manifestaba en el acto constituyente y en el dere$\mathrm{cho}^{57}$. Bajo este presupuesto, la definición del derecho, su administración y su interpretación fueron un asunto institucional del cual el ciudadano común estuvo totalmente excluido. Los discursos legales eran vistos como pertenecientes al ámbito del poder estatal y, en consecuencia, eran objeto de la misma desconfianza con la que se miraba al Estado, al gobierno y sus componentes. No obstante, dada la situación de caos político, el discurso jurídico seguía evocando símbolos de esperanza y cambio social. Esto explica que la idea de ciudadanía haya logrado articular cierta identidad nacional (Melo 1992).

\section{Epílogo}

La tercera parte de esta historia de la relación entre los derechos y el poder político falta por ser contada. Es la historia que ha sido escrita por la Corte Constitucional desde su creación en 1991. Desde entonces el péndulo se ha movido nuevamente hacia el polo fáctico y social de la interpretación jurídica, ya no para consagrar una costumbre depositaria de los valores tradicionales sino para defender los derechos fundamentales de los individuos a través de un sistema de control constitucional amplio y moderno. Algo de este sistema existía desde tiempo atrás en Colombia con la institución del control constitucional de las leyes, sin embargo, con la constitución de 1991 el poder de los jueces para proteger los derechos se ha extendido a los casos individuales a través de la acción de tutela.

\footnotetext{
${ }^{56}$ Como se verá más adelante, aquí está quizás parte de la explicación de la relación problemática que los partidos, grupos y movimientos de izquierda del continente han mantenido con la democracia representativa y con el derecho. La necesidad política de crear un discurso de oposición frente a gobiernos que reivindican el discurso democrático y el Estado de derecho, les ha conducido a un tipo de lucha política que reivindica con frecuencia valores contrarios a estos postulados

57 "En vista de la multiplicidad difusa del concepto de democracia — dice Martín Kriele (Kriele 1980) - es ciertamente cuestión de estipulación definitoria afirmar, como lo haremos, que la democracia presupone libertad y, por tanto, el Estado constitucional“.
} 
Hoy en día existe un gran debate sobre los alcances y beneficios de este poder de la Corte, que no es otro que un debate sobre si debe existir o no un sistema de control de constitucionalidad como el contemplado por la constitución, es decir, si Colombia debe adoptar o no los principios del constitucionalismo moderno. En este ensayo he querido aportar elementos de juicio históricos y socio-jurídicos para abordar de manera más ilustrada este debate. Sin embargo, estoy convencido de que las razones profundas - los presupuestos teóricos determinantes como dice Jeffry Alexander respecto de las discusiones de teoría social - son de naturaleza política y están relacionados con la posición que se adopte respecto del papel que juega un sistema de control de constitucionalidad en la distribución del poder en el Estado y en la configuración del régimen político.

\section{Referencias bibliográficas}

Abel, Richard. 1982. The Politics of Informal Justice, Academic Press, New York.

Aguilera, Mario, Vega Cantor. 1998. Ideal democrático y revuelta popular. Bogota: Universidad Nacional de Colombia - Cerec.

Aguilera, Miguel. 1960. Raíces lejanas de la independencia. Bogotá: Editorial Kelly.

Arnaud, A-J. 1973. Essai d'analyse Structurale du Code Civil Francais. La Règle du jeu dans la paix bourgoise. Paris: LGDJ.

Basterra y Zabala, Ramón de. 1970. Los navios de la Ilustración: una empresa del siglo XVII. Madrid: Editorial Cultura Hispánica.

Benda-Beckman, Franz von (1979) , . . 1979. Property in Social Continuity: Continuity and Change in the Maintenance of Property Relationships Through Time in Minangkabau West Sumatra. The Hague: Nijhoff.

Benda-Beckman, Franz von and Tanya, Taale (1992) . : . 1992. The Changing Laws of Hospitality: Guest Labourers in the Political Economy of Rural Legal Pluralism. Wageningen, The Netherlands: Agricultural University Wageningen.

Blanco Valdés, Roberto L. 1998. El valor de la Constitución. Madrid: Alianza Universidad.

Bolívar, Simón. 1979. Obras Completas. 2 ed. Bogotá: Fica, Tiempo Presente, Ecoe Ediciones.

Braudel, Fernand. 1968. La Historia y las ciencias sociales. Madrid.

Bravo Lira, Bernardino. Codificación civil en Iberoamerica y en la península Ibérica, 1827-1917. Derecho Nacional y europeización. In Fuentes de la codificación iberoamericana, edited by A. Levaggi. 
Burke, Edmundo. 1912. Reflexions on the Revolution in France. Oxford.

Bushnell, Philip. 1976. Los usos del modelo: la generación de la independencia y la imagen de Norteamérica. Revista de Historia de América 82.

Carrera Damas, Germán. 1971. La crisis de la sociedad colonial venezolana, Caracas: Universidad Central de Venezuela. Caracas: Universidad Central de Venezuela.

Carter, James Coolidge. 1884. The Proposed Codification of our Common Law.

Chance, John K. 1982. Razas y Clases de Oaxaca colonial, México. México.

Charles, Cook M. 1981. The American Codification Movement: A study of Antebellum Law Reform: Westport.

Ciriza, Alejandra. 2000. La Formación de la conciencia social y política de las mujeres en el siglo XIX latinoamericano. Mujeres, Política Y Revolución: Juana Azurduy y Manuela Saenz. In El Pensamiento Social y Político Iberoamericano del Siglo XIX, edited by A. Roig. Madrid: Trotta.

Clavero, Bartolomé. 1994. La ley del código: transplantes y rechazos constitucionales por España y por América. Quaderni Fiorentini 23:80-194.

Cutter, Charles R. 1999. The legal Culture of Spanish America on the Eve of independence. In Judicial Institutions in Nineteenth-Century Latin America, edited by E. Zimmermann. London: University of London.

Da Matta, Roberto. 1987. The Quest for Citizenship in a Relational Universe. In State and Society in Brazil, edited by J. D. W. e. al. Boulder Colorado: Westview Press.

Díaz López, Laurentino. 1989. El Derecho en América en el periodo hispánico. Cidad de Panamá: Universidad Santa María de la Antigua.

Forkosch, Morris. 1989. Custom in American. Paper read at Law in Receuils de la Société Jean Bodin.

Gamio, Manuel, ed. 1958. Legislación indígena de México. México.

García-Gallo, Alfonso. 1967. Problemas metodológicos de la historia del derecho indiano. Revista del instituto Interamericano de Derecho Ricardo Levene 18. 1972. La ley como fuente del derecho en Indias. In Estudios de Historia del derecho indiano. Madrid.

Garrido, Margarita. 1993. Reclamos y Representaciones. Bogotá: Banco de la República.

Gómez Hoyos, Rafael. 1962. La revolución granadina de 1810: ideario de una generación y de una época. Bogotá: Editorial Temis.

Góngora, Mario. 1951. El estado en el derecho indiano. Epoca de fundación 1492-1570. Santiago de Chile.

Grossi, Paolo. 1991. Abslolutismo jurídico y derecho privado en el siglo XIX. Rivista di storia del diritto Italiano 64:5-17.

Guzmán Brito, Alejandro. 1982. Andrés Bello codificador. Historia de la fijación y codificación del derecho civil en Chile. Santiago. 
Haring, Clarence Henry. 1947. The Spanish empire in America. New York: Harbinger Books ed.

Hernández Gil, Antonio y Enrique Zuleta. 1976. El tratamiento de la Costumbre en la codificación.

Hooker, M. 1975. Legal Pluralism: An Introduction to Colonial and Neo-Colonial Laws. Oxford: Clarendon Press.

Irazábal, Carlos. 1939. Hacia la democracia: contribución al estudio de la historia económico-político-social de Venezuela. México: Editorial Morelos.

Irving, Leonard A. 1953. Los libros del conquistador. México.

Izard, Miquel. 1990. América Latina siglo XIX: violencia subdesarrollo y dependencia. Madrid: Editorial Síntesis.

Jacobson, J. Mark. 1932. The Development of American Political Thought. New York: Appleton-Century-Crofts.

Jaramillo Uribe, Jaime. 1996. El Pensamiento Colombiano en el Siglo XIX. Bogotá: Planeta.

Jaramillo Vélez, Rubén. 1998. Colombia: la modernidad postergada. Bogotá: Argumentos.

Jordán Pardo, Roberto. 1990. Poblaciones indígenas de América Latina y el Caribe. México.

Keen, Benjamin. 1996. Latin American Civilization History and Society, 1492 to the Present, edited by B. Keen. Boulder Colorado: Westview Press.

König, Hans Joachim. 1994. En el camino hacia la nación: nacionalismo en el proceso de formación del Estado Y de la nación de la Nueva Granada, 1750 A 1856. Bogotá: Banco de la República.

Kriele, Martín. 1980. Introducción a la teoría del Estado. Buenos Aires: Ediciones Depalma.

Levine, Ricardo. 1956. El mundo de las ideas y la Revolución Hispanoamericana de 1810. Santiago: Editorial Jurídica de Chile.

Lewin, Boleslao. 1967. Rousseau y la independencia de Argentina y América. Buenos Aires: Eudeba Editorial Universitaria.

Linz, Juan, Alfred Stepan. 1996. Problems of Democratic Transition and Consolidation; Southern Europe, South America, Post-Communict Europe. BaltimoreLondon: The Johns Hopkins University Press.

Lipset. 1986. Values, Education and Entrepreneurship. Promise of Development Theories of Change in Latin America 39.

Lynch, John. 1987. Hispanoamérica, 1750-1850: ensayos sobre la sociedad y el estado. Bogotá: Universidad Nacional de Colombia.

Maniquis, Robert M. et al. 1989. La revolución francesa y el mundo ibérico. Madrid: Quinto Centenario y Tuner.

Mcfarlane, Anthony. 1997. Colombia antes de la independencia: Economía, sociedad y política bajo el dominio borbón. Bogotá: Banco de la República- El Ancora editores. 
Merryman, John Henry, David S. Clark, John O. Haley , 1994. 1994. The civil law tradition : Europe, Latin America, and East Asia. Charlottesville: Michie Co.

Moore, Sally F. 1978. Law as Process: Anthropological Approach. London: Routledge and Kegan Paul.

Moore, Sally Falk. 1986. Social Facts and Fabrications: Customary Law on Kilimanjaro 1880-1980. Cambridge: Cambridge University Press.

Nino, Carlos Santiago. 1989. Transition to Democracy, Corporatism and Constitutional reform in Latin America. University of Miami Law Review. 44:129-164.

. 1992. In país al margen de la ley. Buenos Aires: Emecé Editores.

Ocampo Lopez, Javier. 1983. El proceso ideológico de la emancipación: las ideas de génesis, independencia, futuro e integración en los orígenes de Colombia. Bogotá: Tercer Mundo Editores.

O'Donnell, Guillermo. 1998. Polyarchies and the (Un)Rule of Law in Latin America, at Notre Dame.

Ortiz Caballero, René. 1989. Derecho Y Ruptura: A Propósito Del Proceso Emancipador Del Perú Del Ochocientos. Lima: Pontificia Universidad de Lima.

Ortiz, Sergio Elías. 1960. Franceses en la independencia de Colombia, Academia Colombiana de Historia. Vol. XIX, Biblioteca Eduardo Santos. Bogotá: Editorial Kelly.

Ots Capdequi, José María. 1940. Estudio del derecho español en las indias. Bogotá.

Ots Capdequí, José María. 1967. Historia Del Derecho Español En América Y Del Derecho Indiano. Bogotá: Biblioteca Jurídica Aguilar.

Pérez, Joseph. 1989. La revolución francesa y la independencia de las colonias hispanoamericanas. Cuadernos Americanos 18.

Pospisil, L. 1971. Anthropology of Law. New York.

Robertson, William Spence. 1939. France and Latin-American Independence. Baltimore: The Johns Hopkins Press.

Rodríguez, M. 1976. La revolución americana de 1776 y el mundo hispánico. Madrid.

Romero, José Luis. 2001. Campo Y Ciudad : Las Tensiones Entre Dos Ideologías. In Situaciones E Ideologías En América Latina. Medellín: Universidad de Antioquia.

2001. Situaciones e ideologías en América Latina. Medellín: Universidad de Antioquia. ca Ayacucho.

Ruiz, Beatriz. 1989. Reflexiones sobre la revolución francesa y América Latina. Cuadernos Americanos 17. 
Samper, José María. 1969. Ensayo sobre las revoluciones políticas y la condición social de las repúblicas colombianas. Bogotá: Universidad Nacional.

Skinner-Kleé, Jorge. 1954. Legislación indigenista de Guatemala. México: Instituto Indigenista Interamericano.

Snyder, Francis. 1981. Capitalism and Legal Change: An African Transformation. New York: Academic Press.

Tau Anzoátegui, victor. 1970. La costumbre como fuente del derecho indiano en los siglos XVI y XVII. Paper read at III congreso del Instituto Internacional de Historia del Derecho Indiano, at Madrid.

Tau Anzoátegui, Victor. 1992. La Ley en América Hispánica. Vol. 6. Buenos Aires: Academia Nacional de Historia.

Tejada, Francisco. 1955. El pensamiento político de los fundadores de la Nueva Granada. Sevilla: GEHA.

Terán, Juan B., ed. 1981. Obras completas. Vol. VIII. San Miguel de Tucumán.

Tocqueville, Alexis. 1972. El antiguo régimen y la Revolución. México: Fondo de Culturta Económica.

Touraine, Alain. 1988. La Parole et le Sang. Politique et société en Amérique Latine. Paris: Odile Jacob.

Uprimny, Leopoldo. 1953. Capitalismo calvinista o romanticismo semiescolástico de los préceres de la independencia colombiana: Réplica al profesor Alfonsol López Michelsen. Universitas.

1971. El pensamiento filosófico y político en el Congreso de Cúcuta. Bogotá: Instituto Caro y Cuervo.

Williams, Robert A. 1990. The American Indian in Western Legal Thought: The Discourses of Conquest,. New York: Oxford University Press. 